\title{
Evaluation of ready-to-use SMLS and DWS devices to study acid-induced milk gel changes and syneresis
}

\author{
Anne Rohart ${ }^{1}$ - Camille Michon ${ }^{1}$. \\ Jérôme Confiac $^{1}$ - Véronique Bosc ${ }^{1}$
}

Received: 17 July 2015 /Revised: 27 January 2016 / Accepted: 15 February 2016 /

Published online: 9 March 2016

C) INRA and Springer-Verlag France 2016

\begin{abstract}
The aim of this study was to examine the potential of ready-to-use multi-speckle diffusing wave spectroscopy (MS-DWS) and static multiple light scattering (SMLS) devices to follow the acid-induced gelation of milk, as well as to detect the appearance of gel syneresis. These light-scattering techniques, MS-DWS and SMLS, have been used in comparison to the classical rheology to study acid milk gel formation and syneresis detection. A systematic study of the effects of heat treatment of milk on the formation of acid gels was conducted. Results obtained by DWS and rheology showed excellent correlation in good agreement with the existence of a link between particle dynamics measured by DWS and the macroscopic viscoelastic response of the gel. Moreover, both light scattering techniques showed ability to detect gel shrinkage due to their high sensitivity to particle mobility. DWS allowed evidencing wheying-off along the tubes' glass walls, while SMLS performed well in detecting syneresis on gel surface or confined in localized zones of the glass walls. The results were discussed in light of a proposed model considering gel syneresis as regards of gel properties. Light-scattering techniques proved to be very efficient tools to detect syneresis in acid milk gels and thus can be of great interest in preventing this mechanism.
\end{abstract}

Keywords Gelation $\cdot$ Rheological properties $\cdot$ DWS $\cdot$ Syneresis

Camille Michon

Camille.Michon@agroparistech.fr

1 UMR Ingénierie Procédés Aliments, AgroParisTech, Inra, Université Paris-Saclay, F-91300 Massy, France 


\section{Introduction}

The behaviour of acid milk gels has been a topic of interest for a long time, likely for their great economic importance in the dairy industry. The process of acid-induced milk gelation results from the destabilization of colloidal particles (the casein micelles) and leads to a network of casein strands aggregated through isoelectric precipitation (Heertje et al. 1985; Lucey et al. 1997a). The pH reduction can be simulated by the use of glucono- $\delta$-lactone which mimics the acidification kinetics obtained with bacterial culture (Lucey et al. 1998a).

In practice, heat treatment is generally applied to milk for safety reasons. However, it has a marked influence on rheology, microstructure and gel syneresis (Livney et al. 2003). It is well-established that milk heating causes a denaturation of the whey proteins and their partial attachments to the casein micelles which participate to the gel network formation (Donato and Guyomarc'h 2009; Famelart et al. 2004; Guyomarc'h et al. 2003). As a result, the strength and number of bonds between protein particles increased, leading to increased storage modulus, $\mathrm{G}^{\prime}$, values compared to gels made from unheated milk (Lucey et al. 1999).

Studies on milk acidification are mainly performed using rheology, microscopy or conventional light scattering techniques (Gastaldi et al. 1996; Lucey et al. 1997b). Later on, diffusing wave spectroscopy (DWS) has been extensively used in a number of laboratories to easily determine the structure in situ during the evolution of the system without disturbing the sample or needing a dilution (Corredig and Alexander 2008; Horne 1999; Nicolai 2007). Nevertheless, it should be noted that most of the studies concerned only the earliest stages of acid gelation and did not cover structure changes such as network rearrangements in mature gels which can lead to whey expulsion (Alexander and Dalgleish 2007; Hemar et al. 2004).

Syneresis, apart from being considered as a quality defect in the production of set yoghurts, certainly causes problems in the study of acid gelation as regards the rheological characteristics because of gel slippage. In that case, the decrease in the dynamic moduli during ageing of the gels is mainly the result of spontaneous wheying-off due to the loss of the ability of the gel to entrap all of the serum phase (Aichinger et al. 2003; Haque et al. 2001; van Vliet et al. 2004a; Xu et al. 2008). Although numerous empirical methods have been developed to quantify spontaneous whey separation in set gels such as whey determination by siphon, drainage and centrifugation (Aichinger et al. 2003; Lucey et al. 1998b), no systematic technique has been used so far to detect the appearance of syneresis during the acidification process.

The objective of the current study was to investigate the potential of ready-to-use multi-speckle diffusing wave spectroscopy in backscattering mode (MS-DWS) and static multiple light scattering (SMLS) devices to monitor the acid-induced gelation of milk, as well as to detect the appearance of gel syneresis. For this purpose, a multitechnique approach was used to highlight the contribution of the light scattering techniques, compared to rheological measurements, to study acid-induced gels made from milk previously heated at various temperatures. Syneresis detection by light scattering techniques was discussed on the basis of the understanding of the structural differences between the gels. 


\section{Materials and methods}

\subsection{Preparation of the gels}

Skim milk with 46 g. $\mathrm{kg}^{-1}$ protein was reconstituted by dispersing low-heat skim milk powder ( $\mathrm{CH}$ low heat, Ingredia, Arras, France) in Milli-Q water under continuous stirring for $1 \mathrm{~h}$ at room temperature. The reconstituted skim milk was then left to fully hydrate overnight at $4{ }^{\circ} \mathrm{C}$. Heat treatment of the milk, when necessary, was performed in a water bath at 70,80 or $90{ }^{\circ} \mathrm{C}$ for $7 \mathrm{~min}$, followed by immediate cooling at $43{ }^{\circ} \mathrm{C}$.

Milk acidification was achieved by the addition of $1.25 \mathrm{wt} \%$ glucono- $\delta$-lactone (GDL) (Sigma Chemicals, St Louis, MO, USA) at a temperature of $43{ }^{\circ} \mathrm{C}$ with stirring. Stirring was continued for one minute, after which aliquots were transferred to the DWS and SMLS cells and to the rheometer cup where their behaviours during acidification were monitored. The $\mathrm{pH}$ decline was followed in the meantime using a pH-meter Consort D130 multiparameter analyzer (Turnhout, Belgium). Plots of the measured $\mathrm{pH}$ against time for three repeated runs were averaged and analyzed in order to provide interpolated $\mathrm{pH}$ values for all the experimentally-measured points in the DWS and SMLS instruments and rheometer. When a $\mathrm{pH}$ value of $4.6( \pm 0.05)$ was obtained, the set acid milk gels were immediately stored at $4{ }^{\circ} \mathrm{C}$ overnight until required analysis. Proportion of set acid milk gels at $\mathrm{pH} 4.6$ that were subjected to syneresis were calculated from 12 samples for acid milk gels from unheated milk or milk heat-treated at 70 or $90{ }^{\circ} \mathrm{C}$ and 27 samples for acid milk gels from milk heattreated at $80{ }^{\circ} \mathrm{C}$.

\subsection{Instrumental characterization}

\subsubsection{Static multiple light scattering (SMLS) measurements}

Measurements were carried out using a Turbiscan LAB ${ }^{\circledR}$ and a Turbiscan Classic MA $2000^{\circledR}$ instruments (Formulaction, France). Turbiscan LAB ${ }^{\circledR}$, which is thermostated, was used to follow milk acidification; whereas Turbiscan Classic MA $2000^{\circledR}$ was used to detect syneresis during milk gelation. Both devices are based on the same principle.

Backscattering values at $880 \mathrm{~nm}$ (Turbiscan $\mathrm{LAB}^{\circledR}$ ) and $850 \mathrm{~nm}$ (Turbiscan Classic MA $2000^{\circledR}$ ) were acquired every $40 \mu \mathrm{m}$ along a $40 \mathrm{~mm}$ height of sample at different time intervals. The backscattering profile intensity along the sample height gives a qualitative indication of the particle sizes and concentrations. It therefore allows the detection of the evolution of the distribution and movements of the particles. Then, this ready-to-use device allows calculating the photon transport mean free path $1^{*}$, which is inversely proportional to the square root of the backscattering intensity value. The value of $1^{*}$ depends on particle diameter and phase volume (Eq. 1) (Mengual et al. 1999).

$$
l^{*}(d, \phi)=\frac{2 d}{3 \phi(1-g) \mathrm{Qs}}
$$

With $d$ the particle mean diameter, $\phi$ the phase volume, $g$ the asymmetry factor and Qs the scattering efficiency factor arising from Mie theory. 
Milk samples (20 and $4 \mathrm{~mL}$ for Turbiscan $\mathrm{LAB}^{\circledR}$ and Classic MA $2000^{\circledR}$, respectively) were poured in glass tubes (inner diameter of 27.5 and $6.1 \mathrm{~mm}$ for Turbiscan LAB $^{\circledR}$ and Classic MA $2000^{\circledR}$, respectively) which allow displaying the same height. The Turbiscan $\mathrm{LAB}^{\circledR}$ apparatus was equilibrated at $43{ }^{\circ} \mathrm{C}$ before measurement. Sample cells were then immediately placed in the apparatus and the milk was left to acidify until the $\mathrm{pH}$ of 4.6 was reached. Measurements were performed every minute. For analysis with the Turbiscan Classic MA $2000^{\circledR}$, tubes were preheated and maintained at $43{ }^{\circ} \mathrm{C}$ in a dry bath during the time of acidification and tube scanning was carried out at different time intervals during this process. Measurements were performed in triplicate. Typical backscattering curves obtained during milk acidification over different times are shown in Fig. 1. A modification of backscattering values appeared from $0.2 \mathrm{~h}$ compared to the initial time (time $=0 \mathrm{~h}$ ). However, the backscattering level was almost constant along the sample height from 0 to $40 \mathrm{~mm}$ whatever the time of measurement. Thus, backscattering values were averaged between 15 and $30 \mathrm{~mm}$ of sample height in order to follow backscattering as a function of time during acidification.

\subsubsection{Multi-speckle diffusing wave spectroscopy (MS-DWS) measurements}

The diffusing wave spectroscopy instrument was a Rheolaser LAB6 ${ }^{\circledR}$ (Formulaction, France) which is based on dynamic light scattering (DLS) extended to an opaque media in backscattering mode. For multi-speckle DWS experiments, a coherent laser beam $(650 \mathrm{~nm})$ was applied to the sample and the light is multi-scattered by the particles, which leads to interfering backscattered waves. An interference image called "Speckle image" is detected by a multi-pixel detector. The distance between two successive speckles are measured and computed using a correlation function. It should be noted that the use of the backscattering mode allowed the analysis of opaque samples without being influenced by the contact surface due to the high thickness of the sample in the tube.

According to a patented algorithm (Brunel 2010) adapted to the cylindrical geometry of the glass cell and the backscattering mode, the mean square displacement (MSD) is determined from an autocorrelation function derived from Weitz and Pine (1993)

Fig. 1 Backscattering values versus tube height of milk heat-treated at $80{ }^{\circ} \mathrm{C}$ and acidified with $1.25 \mathrm{wt} \% \mathrm{GDL}$ at $43{ }^{\circ} \mathrm{C}$ in a glass tube using a Turbiscan LAB $^{\circledR}$. The schematic representation of the tube illustrates the top and bottom of the tube. The grey dotted lines and the arrow indicate the sample height interval where the backscattering value was averaged for the measurements of Fig. 3

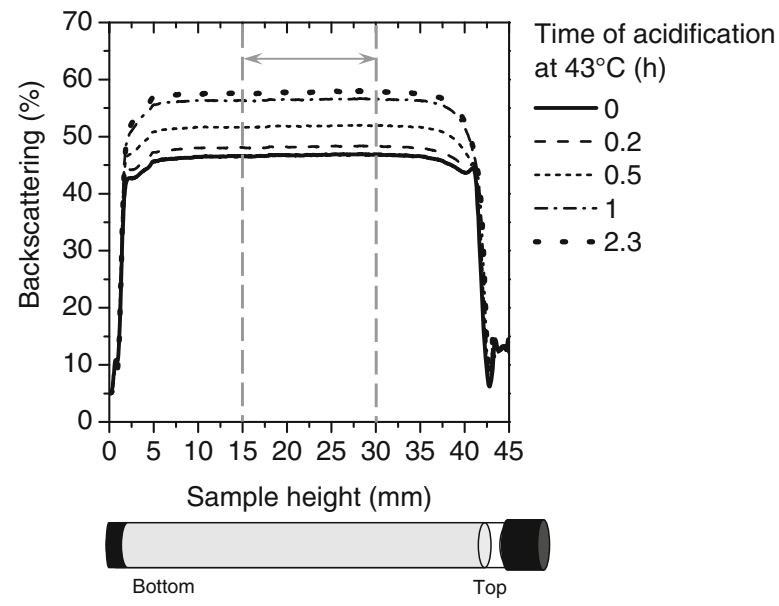


approach and depending on the turbidity. MSD of particles inside a media is directly linked to the viscoelastic properties of the samples. Thus, measuring the particle Mean Square Displacement (MSD) versus decorrelation time provides a viscoelastic parameter, the elasticity index (EI) following Eq. 2.

$$
\mathrm{EI}=\frac{1}{6 \delta^{2}} * \frac{d_{e}}{d}
$$

where $6 \delta^{2}\left(\mathrm{~nm}^{2}\right)$ is the mean value of MSD at low decorrelation times $(<0.1 \mathrm{~s}), d(\mu \mathrm{m})$ is the mean particle diameter measured by laser diffraction and $d_{e}$ the diameter of a model particle used for calibration $\left(\mathrm{TiO}_{2}\right)\left(d_{e}=1 \mu \mathrm{m}\right)$.

This technique enables the detection of local particle mobility due to thermal agitation which is related to viscoelastic behaviour. Contrary to measurements carried out with Turbiscan apparatus, the laser of the Rheolaser LAB6 ${ }^{\circledR}$ analyzed the sample only at one height of $24 \mathrm{~mm}$.

Elasticity Index $\left(\mathrm{EI}, \mathrm{nm}^{-2}\right)$ is computed from the elastic level of the MSD curves at short decorrelation timescales, i.e. $<0.1 \mathrm{~s}$, and can be related to the solid-like behaviour of the sample. $20 \mathrm{~mL}$ of milk samples were poured at $43{ }^{\circ} \mathrm{C}$ in glass tubes (inner diameter of $27.5 \mathrm{~mm}$ ) and EI was followed as a function of time during acidification until a $\mathrm{pH}$ of 4.6 .

\subsubsection{Rheological measurements}

In addition to SMLS and MS-DWS experiments, rheological properties were also characterized in parallel. Rheological measurements were carried out using a MCR301 stress-controlled rheometer (Anton Paar, Germany). The measurements were performed with a coaxial sand cylinder geometry $(\mathrm{R} 1 / \mathrm{R} 2=0.92)$ consisting of a rotating inner cylinder with a $40 \mathrm{~mm}$ immersed height. After introducing the milk sample into the measurement cell, a thin layer of low-viscosity silicone oil was applied on the surface of the sample to prevent evaporation. The development of storage modulus $\left(\mathrm{G}^{\prime}\right)$ was monitored in the linear domain ( $1 \%$ strain) at a constant frequency of $1 \mathrm{~Hz}$ at $43{ }^{\circ} \mathrm{C}$ until the $\mathrm{pH}$ of 4.6 was reached.

\section{Results}

\subsection{Acidic gelation of milk}

\subsubsection{Study of the gelation process using DWS, SMLS and rheology}

Typical mean square displacement (MSD) profiles versus decorrelation time obtained by DWS of skim milk heated at $80{ }^{\circ} \mathrm{C}$ and gelled after addition of $1.25 \mathrm{wt} \%$ GDL are shown as a function of ageing time in Fig. 2a. The evolution of the MSD with ageing is characteristic of the changes in viscoelastic properties. Upon acidification, a decrease in the levels of the MSD curves with acidification time (grey arrow, Fig. 2a) indicates a change in viscoelastic behaviour. At the beginning of the incubation time, MSD values increased linearly with decorrelation time. As the acidification proceeded, the level and 
a

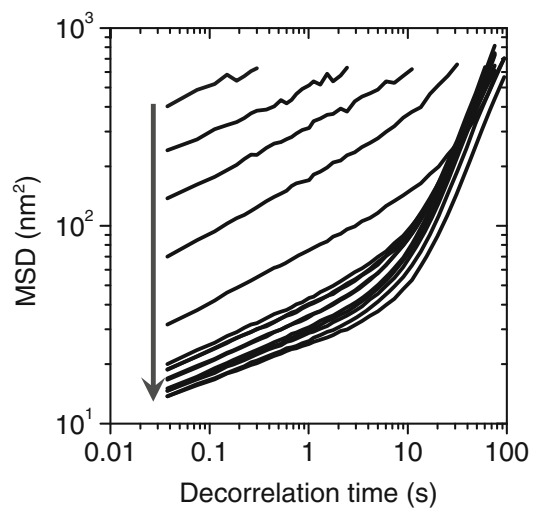

b

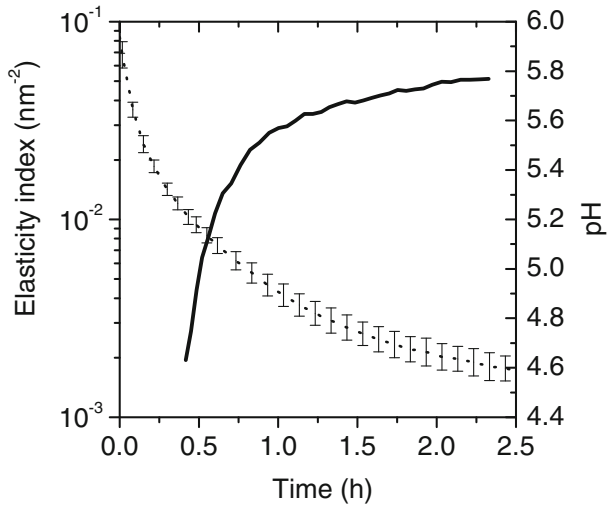

Fig. 2 a Mean square displacement (MSD) curves; b elasticity index (solid line) and pH (dotted line) as a function of time during acidification by $1.25 \mathrm{wt} \% \mathrm{GDL}$ of skim milk heat-treated at $80{ }^{\circ} \mathrm{C}$. The arrow indicates the evolution of the MSD curves with time. $\mathrm{pH}$ values are mean of three repeated measurements, error bars give an indication of the reproducibility of the $\mathrm{pH}$ decrease kinetic

profile of the MSD curves evolved with two different domains of evolution with the decorrelation time. At short decorrelation times $(<5 \mathrm{sec})$, the level of MSD decreased and tended to level off as the gelation occurred. Therefore, the MSD evolved hardly with the decorrelation time and was considered as an elastic plateau. At long decorrelation times, the MSD signal increased abruptly and also levelled off with time of acidification. The uniform linear increase of MSD with decorrelation time at the beginning of the process can be attributed to a liquid-like behaviour. Indeed, at neutral $\mathrm{pH}$ casein micelles are considered as dispersed particles that are completely free to move in the medium. Then, the appearance of an elastic plateau at low decorrelation times and longer acidification times can be related to a dominant solid behaviour. After adding GDL to the milk, the $\mathrm{pH}$ decreased progressively (Fig. 2b), which led to a destabilization of the casein micelles in the form of a continuous gel network (Heertje et al. 1985; Holt 1992). Thus, milk acidification resulted in the hindrance of the casein micelles mobility due to gel network formation.

When interpreting the MSD profiles, MSD values can be computed from the level of the plateau at low decorrelation times to provide elasticity indexes at different acidification times (Fig. 2b). The elasticity index could only be measured from $0.42 \mathrm{~h}$ and then it immediately started to increase steadily until it began levelling off towards after $0.75 \mathrm{~h}$ to the end of the acidification. In parallel, the $\mathrm{pH}$ decrease after addition of $1.25 \mathrm{wt} \%$ GDL as a function of time was followed (Fig. 2b). The initial $\mathrm{pH}$ of the sample was 6.7 and dropped to approximately 4.6 after $2.5 \mathrm{~h}$.

It should be noted that the first elasticity index was measured at a $\mathrm{pH}$ of 5.2, which corresponds to the beginning of casein particles aggregation for a medium-heated milk and thus to the critical value for gelation (Lucey et al. 2001). As acidification proceeded, the progressive strengthening of the gel network was responsible for the increase in elasticity index.

During the acidification process, $\mathrm{pH}$ and time were not linearly related (Fig. 2b) because of the progressive hydrolysis of the glucono- $\delta$-lactone and, therefore, the gradual reduction in milk $\mathrm{pH}$. As a consequence, it was preferable to plot the measured 
parameters as functions of $\mathrm{pH}$ rather than time. Indeed, gelation is $\mathrm{pH}$-dependent. The kinetics of acid gel formation in skim milk induced by hydrolysis of glucono- $\delta$-lactone can be determined using several techniques. Two light scattering techniques, MS-DWS and SMLS, were compared to the classically-used oscillatory rheology (Fig. 3a-c). The change in storage modulus during the $\mathrm{pH}$ decrease of milk heat-treated at $80{ }^{\circ} \mathrm{C}$ and acidified with $1.25 \mathrm{wt} \% \mathrm{GDL}$ at $43{ }^{\circ} \mathrm{C}$ is shown in Fig. 3a. Gel formation was detected as the first measurable response to the rheometer which corresponded to a $\mathrm{pH}$ of around 5.2. Then, on lowering the $\mathrm{pH}$ the values of $\mathrm{G}^{\prime}$ sharply increased up to $\mathrm{pH} 5$ until a maximum was reached in viscoelastic moduli. This result is in good agreement with previous results. Indeed, it has been shown that the gelation $\mathrm{pH}$ of acid gels made from

Fig. 3 Evolution during acidification by $1.25 \mathrm{wt} \%$ GDL of skim milk heat-treated at $80{ }^{\circ} \mathrm{C}$ of a the storage modulus, $\mathrm{G}^{\prime}$; $\mathbf{b}$ the elasticity index, EI; (c) the backscattering averaged between 15 and $30 \mathrm{~mm}$ sample height (see Fig. 1). Squares, circles and triangles represent repeated independent experiments. Error bars represent standard deviations for three replicate analyses

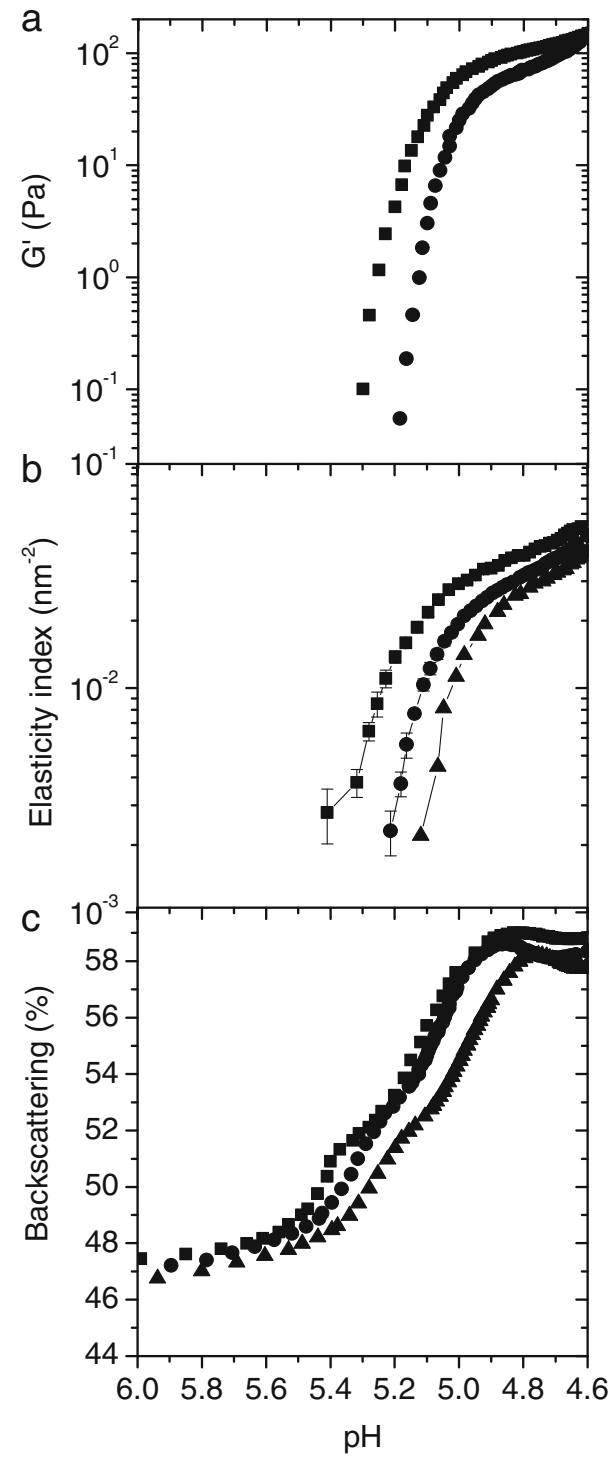

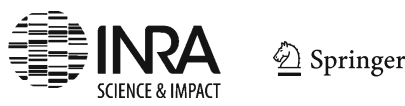


medium-heated milk was around 5.2, and it was followed by abrupt changes in the slopes of the $\mathrm{G}^{\prime}$ versus pH curves (Lucey et al. 1998a; Xu et al. 2008).

The evolution of elasticity indexes calculated from MSD curves obtained by MSDWS technique followed the same pattern (Fig. 3b). There was found a drastic increase from $\mathrm{pH} 5.2$ followed by a more progressive increase in elasticity index at the end of acidification. It should be reminded that repeatability, which is represented by the error bars, was obtained for three replicate analyses whereas reproducibility was obtained for three separate gel manufactures. Thus, it is interesting to observe that reproducibility of gel manufacture was difficult to achieve accurately, although repeatability of MS-DWS measurements was satisfactory. As for rheological experiments, no measurable response could be obtained before reaching $\mathrm{pH}$ 5.2. Indeed, the charged couple device (CCD) could not numerically calculate the multi-speckle correlation function at the very beginning of the acidification process because of the simultaneous detection of a too-large number of speckles (Corredig and Alexander 2008). The changes in the speckle image with time were too quick to be collected by the multi-pixel detector (CCD camera, $27 \mathrm{~Hz}$ ). Complementary analyses have shown that measurements could be recorded from the beginning of the experiment using an upgraded device with a faster recording system (data not shown).

Another light scattering technique which is based on static multiple light scattering was used to follow the acid milk gelation with the measurement of backscattering values (Figs. 1 and 3c). Little change was observed in the backscattering values until the $\mathrm{pH}$ had decreased to about 5.5-5.4, after which there was a substantial increase until the value peak reached a maximum. Then, the backscattering values decreased somewhat before becoming constant below $\mathrm{pH}$ 4.8. As for the measurement of the elasticity index (Fig. 3b), the slight shift observed between the backscattering curves was due to the variability of gel manufacture. However, it is important to note that a shoulder between pH 5.4 and 5.2 was observed using SMLS for the three repeated gels.

It is of interest to compare the contribution of each technique to the analysis of the mechanism of acid milk gel formation. Backscattering values from SMLS signals showed unusual trends between $\mathrm{pH} 5.4$ and 5.2 with a shoulder. This tendency has been observed by Ercili-Cura et al. (2013) and it can be related to a change in casein micelles in the range 5.5 to 5.0 with regard to the onset of protein aggregation. When approaching the isoelectric point of the caseins, their solubility decreases leading to an association and a subsequent aggregation at about $\mathrm{pH}$ 5.2-5.0. These mechanisms induced a change in optical properties.

The gelation point close to $\mathrm{pH} 5.2$ obtained by rheology (Fig. 3a) was very similar to the one obtained by DWS measurements (Fig. 3b), which is consistent with the literature (Horne et al. 2003). In rheology, the transition from liquid to solid is classically indicated by the crossover where $G^{\prime}$ becomes greater than $G^{\prime}$, and thus a self-supporting network is formed. Considering DWS measurements, the sign of gelling mechanism was evidenced by the hindering and ultimately halting of particle motion (Alexander and Dalgleish 2007; Horne et al. 2003; Stradner et al. 2001). Therefore, even if DWS is much more sensitive to the dynamics of the particles than macrorheology, these two techniques showed similar behaviours at the beginning of gel formation. Nevertheless, compared to rheometers, DWS and SMLS are non-destructive techniques. Rheological measurements are performed by applying a mechanical stress or deformation to follow the development of the gel (Alexander and Dalgleish 2007; 
Hemar et al. 2004; Nicolai 2007). When studying fragile systems such as milk protein gels, it is likely that the aggregation of the casein micelles is slightly modified by the mechanical forces. Therefore, even if DWS and SMLS have already been used to study gelation, the DWS and SMLS ready-to-use devices were able to analyze the early stages of milk acidification with changes in casein micelles before gelation occurs.

\subsubsection{Correlation between DWS and rheology: effect of heat treatment}

It has been widely reported that milk preheating plays a major role on the structure development and rheological properties of yoghurt gels (Lucey et al. 1999). Therefore, the effects of the heat treatment of milk were studied using both classical rheology and MS-DWS (Figs. 4 and 5) in order to determine if results from both techniques were correlated.

Figure 4 shows the evolution of the storage modulus $\mathrm{G}^{\prime}$ in relation to elasticity index EI during the acidification of milk which was either unheated or heated 7 min at 70, 80 or $90{ }^{\circ} \mathrm{C}$ prior to incubation. Whatever the heat treatment of the milk and except for the very first points, there was a linear increase in $\mathrm{G}^{\prime}$ versus EI when plotted logarithmically as acidification proceeded (Fig. 4) meaning that $\mathrm{G}^{\prime}$ evolves as $\mathrm{EI}^{2.4}$. It has to be pointed out that the increase in EI began earlier than the evolution of storage modulus $\mathrm{G}^{\prime}$. At the beginning of the gelation (low value of $\mathrm{G}^{\prime}$ and EI), EI evolved with the heat treatment, whereas $\mathrm{G}^{\prime}$ remained unchanged (Fig. 4). Thus, at the earlier stages of gel formation, $\mathrm{G}^{\prime}$ was probably underestimated and the measurements probably impacted the very weak gel formation. EI values showed high standard deviations because of the difficulty of the device to track rapidly moving particles in a very low-viscosity medium. However, the use of a more rapid camera, already implemented on new DWS Rheolaser devices, solved this problem.

During milk acidification, the gradually-increasing tendency of the casein micelles to interact either directly or via interactions with denatured whey proteins severely hinders their movement (Alexander et al. 2008). This process has been suggested to be gradual, thus progressively increasing the strength of the interactions between the particles after the aggregation has become well-established (Dalgleish et al. 2004; Sandra et al. 2007). In spite of using two different physically-based techniques, bulk rheology with the increase in $\mathrm{G}^{\prime}$ as well as elasticity index measured by DWS could detect these increasing strengths. However DWS was less gel-destroying and also more

Fig. 4 Plots of the storage modulus, $\mathrm{G}^{\prime}$, as a function of the elasticity index, EI, during acidification by $1.25 \mathrm{wt} \%$ GDL at $43{ }^{\circ} \mathrm{C}$ of unheated milk and milk heat-treated $7 \mathrm{~min}$ at 70,80 or $90{ }^{\circ} \mathrm{C}$. Error bars represent standard deviations for three replicate analyses. The grey dotted line corresponds to a linear adjustment between $\log \mathrm{G}^{\prime}$ and $\log$ EI obtained for the non-heated milk curve

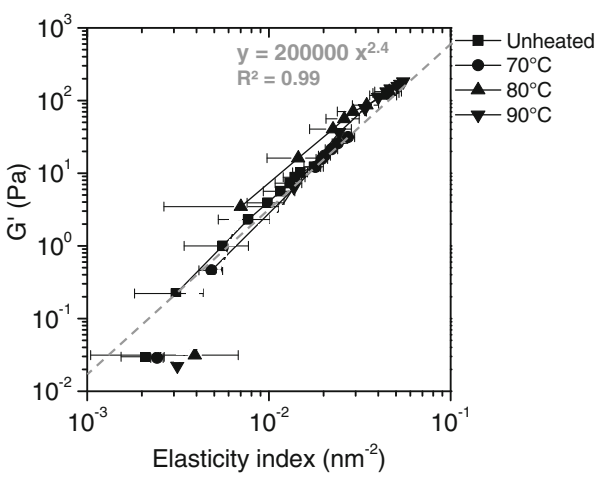


Fig. 5 Values of $\mathrm{G}^{\prime}$ as a function of elasticity index of set acid milk gels at $\mathrm{pH} 4.6$ at the end of acidification from unheated milk or milk heat-treated at 70,80 or $90^{\circ} \mathrm{C}$. Error bars represent standard deviations for three replicate analyses. Empty symbols $(\nabla)$ and $(\Delta)$ correspond to a peculiar gel from milk heat-treated at $90^{\circ} \mathrm{C}$ or at $80^{\circ} \mathrm{C}$, respectively. The grey dotted line corresponds to a linear adjustment between $\log \mathrm{G}^{\prime}$ and $\log \mathrm{EI}$

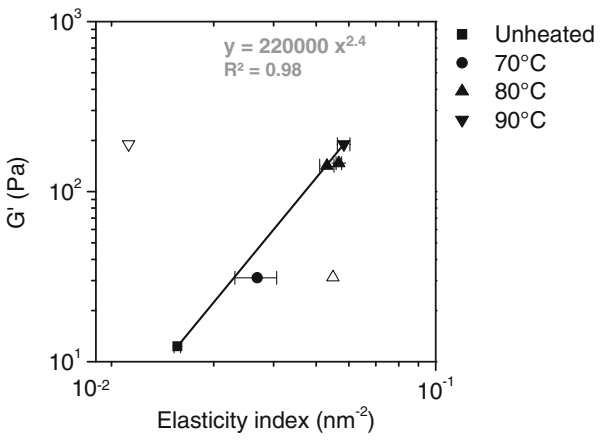

sensitive than rheology in the early stages of gel formation. This could be explained by the macroscopic nature of rheology, where all the components of the system are involved in the network. On the contrary, DWS may detect the change in particle size, i.e. voluminosity of casein micelles during the very early stages of acidification which is not detected by traditional rheometry (Alexander and Dalgleish 2007; Alexander et al. 2008).

In order to discuss more thoroughly the effects of heat treatment on gel properties, values of storage modulus, $\mathrm{G}^{\prime}$, and elasticity index, EI, obtained at the end of the acidification process at $\mathrm{pH} 4.6$ in set gels were replotted logarithmically (Fig. 5). In that way, the linear relation between $\log \mathrm{G}^{\prime}$ and $\log$ EI became apparent. The exponent, 2.4, is of the same order than the value found from the kinetics of acidification in Fig. 4 (exponent=2.4). As expected, the higher the heat treatment of milk, the higher $\mathrm{G}^{\prime}$ and EI.

The strong correlation between the DWS behaviour and storage modulus G' observed here resembles what was previously reported for rennet coagulation mechanism using a lab-built DWS apparatus (Hemar et al. 2004; Sandra et al. 2007). However, acidified milks constituted a questionable case in literature since Dalgleish et al. (cited by Sandra et al. 2007) found no similar relationship whereas Horne et al. (2003) established a linear correlation between DWS and rheological coagulation times. This difference may be explained by various CCD acquisition rates and/or different evolution of the contact of the product with the wall surface which could alter the DWS signal. In this study, the commercial device Rheolaser LAB6 ${ }^{\circledR}$ (Formulaction, France) gave results that were consistent with laboratory-manufactured devices based on theory of DWS spectrometer.

The contribution of heat treatment to the strength of gels made from heated milk was obvious, as rheologically seen with $\mathrm{G}^{\prime}$ as well as with DWS measurements. In gels made from unheated or low-heat-treated milks, the casein particle size is increasing due to the onset of protein aggregation at a pH close to 5.2 (Famelart et al. 2004; Alexander and Dalgleish 2005; Kalab and Emmons 1975). This substantial increase in particle size may explain the greater variations in elasticity index in comparison to storage modulus at the earlier stages of gelation. Indeed DWS shows greater sensitivity to the change in particle size than rheology (Hemar et al. 2004). When heat treatment in the range 80$90{ }^{\circ} \mathrm{C}$ is applied to milk, two types of particles, i.e. denatured whey protein aggregates and heat-induced whey protein- $\kappa$ casein complexes (micelle-bound complexes) participate to the gel network formation, leading to small particle sizes and to a branched 
structure. Therefore, the number of bonds between protein particles, and thus the strength of gels made from heated milk, is higher than those made from unheated milk, as observable by the high values of $\mathrm{G}^{\prime}$ and elasticity indices (Donato and Guyomarc'h 2009; Famelart et al. 2004; Lucey et al. 1999).

Two peculiar observations also obtained at the end of the acidification process at $\mathrm{pH} 4.6$ in set gels and represented by empty symbols $(\nabla$ and $\Delta$ ) were plotted in Fig. 5. That is, firstly, a drastic decrease in the dynamic moduli during gel formation appeared in one acid gel made from milk heated at $80{ }^{\circ} \mathrm{C}(\Delta)$, while the elasticity indexes detected by DWS remained at $0.05 \mathrm{~nm}^{-2}$ for three other repeated gels. And secondly, a very low value of elasticity index was obtained for one of the two gels $(\nabla)$ from milk heated at $90{ }^{\circ} \mathrm{C}$ prior to acidification while $\mathrm{G}^{\prime}$ was at the same level.

It seems reasonable to suggest that the sudden drop in $\mathrm{G}^{\prime}$ (for the higher milk heat treatment), is due to slippage within the measurement cell during the rheological test. When a thin layer of liquid is formed between the walls of the measuring unit of the rheometer and the sample, the gel loses mechanical contact with the cell wall which leads to apparent measured modulus tending to zero (Haque et al. 2001; Xu et al. 2008). Shrinkage of the gel during the measurement may have led to wheying-off.

For the second case dealing with a gel made with milk previously treated at $80{ }^{\circ} \mathrm{C}$, the decrease in EI should be considered as an increase in MSD values due a sudden increase in particle motion at the point of measurement. It should be remembered that for DWS measurements, the laser is focused at a height of $24 \mathrm{~mm}$.

\subsection{Syneresis detection during gel formation}

In order to explore the possible reasons for the appearance of two peculiar cases as seen in Fig. 5 (empty symbols $(\nabla$ and $\Delta)$ ) more precisely, further experiments were carried out using Turbiscan Classic MA 2000 ${ }^{\circledR}$ which allows analyzing the sample along its height (Fig. 6a and b). Figure 6a shows the evolution of backscattering during the acidification of milk heated at $70{ }^{\circ} \mathrm{C}$ and acidified with $1.25 \mathrm{wt} \% \mathrm{GDL}$ at $43{ }^{\circ} \mathrm{C}$ over different times as a function of the sample height. When comparing the profiles to initial time, the backscattering level increased as acidification proceeded. This result is consistent with the behaviour of backscattering observed in Figs. 1 and 3c in spite of using two different SMLS apparatuses (Turbiscan LAB ${ }^{\circledR}$ and Turbiscan Classic MA $2000^{\circledR}$ ) based on the same principle for the experiments. Although backscattering levels remained constant along the sample height during gel formation (Fig. 6a), a slight decrease in backscattering values appeared at the top of the tube at the end of acidification. This decrease intensified after $24 \mathrm{~h}$ storage at $4{ }^{\circ} \mathrm{C}$ (Fig. 6c). The interactions between the protein particles may have increased during the storage of $24 \mathrm{~h}$ at $4{ }^{\circ} \mathrm{C}$, which may have contributed to increase the porosity of the gel, thus facilitating the moving of whey outside of the network. This behaviour can be attributed to the decrease in particle concentration and thus to the formation of a serum layer devoid of particles.

Figure $6 \mathrm{~b}$ shows the variation of backscattering during the acidification of milk heattreated at $90{ }^{\circ} \mathrm{C}$ and acidified with $1.25 \mathrm{wt} \%$ GDL at $43{ }^{\circ} \mathrm{C}$ over different times as a 

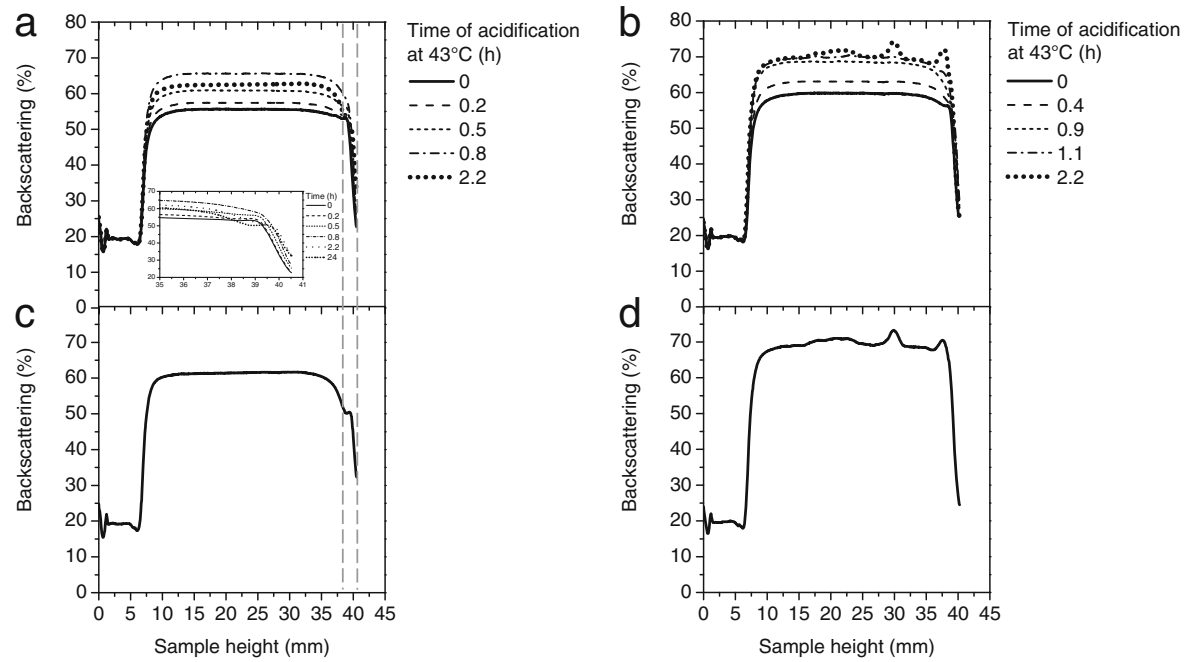

Fig. 6 Backscattering values of a milk heat-treated at a $70{ }^{\circ} \mathrm{C}$; b $90{ }^{\circ} \mathrm{C}$ acidified with $1.25 \mathrm{wt} \%$ GDL at $43{ }^{\circ} \mathrm{C}$ along its height in a glass tube over acidification time (c) and $\mathbf{d}$ after a storage of $24 \mathrm{~h}$ at $4{ }^{\circ} \mathrm{C}$, respectively. Grey dotted lines highlight appearance of a serum layer on the surface of the gel after $24 \mathrm{~h}$. The inset in a shows the upper part of the sample tube over acidification time and after $24 \mathrm{~h}$ at $4{ }^{\circ} \mathrm{C}$

function of the sample height. Similarly to Fig. 6a, a subsequent increase in backscattering was observed and values were constant along the sample height until $0.9 \mathrm{~h}$ after GDL addition. However, after $1.1 \mathrm{~h}$, evidence of extensive variations of backscattering values along the sample height appeared and it reinforced over time, particularly in the middle and upper parts of the tube. The noisy signal was caused by a nonhomogeneous gel containing whey in confined small cavities. It should be noted that contrary to Fig. $6 \mathrm{c}$, no evolution of the backscattering profile was observed between the end of acidification (Fig. 6b) and after $24 \mathrm{~h}$ of storage at $4{ }^{\circ} \mathrm{C}$ (Fig. 6d). Therefore, the gel network did not evolve at long ageing times, thus maintaining the syneresis level constant and avoiding additional whey separation during storage.

In order to generalize the two observed profiles obtained by SMLS (Fig. 6a and b), the percentage of acid milk gels subjected to surface and/or wall syneresis was calculated as a function of heat treatment applied to the milk prior to acidification (Fig. 7). Evidence of extensive syneresis on the surface due to the formation of a serum layer was shown for gels from unheated milk or milk heat-treated at $70{ }^{\circ} \mathrm{C}$. In contrast there was a tendency towards a wall syneresis in the acid gels from more severelyheated, treated milk. Intermediate behaviour was observed for gels from milk heattreated at $80{ }^{\circ} \mathrm{C}$ with a large number of gels subjected to either surface, wall or both type of syneresis. Therefore, low-heat treatment of the milk contributed to syneresis on the gel surface whereas gels obtained from severely heat-treated milk were more prone to wall syneresis.

Syneresis phenomenon was also studied by DWS measurements. Figure 8a shows the developments of elasticity index during acidification measured by DWS for the two repeated gels made from milk heated at $90{ }^{\circ} \mathrm{C}$ corresponding to the gels analyzed in Fig. 5. While the elasticity index continuously increased up to $0.053 \mathrm{~nm}^{-2}$ for one sample, in the second sample a sudden drop in elasticity index just after gel formation was observed at a $\mathrm{pH}$ of 5.05, followed by a noisy signal. Photographs of the two set 


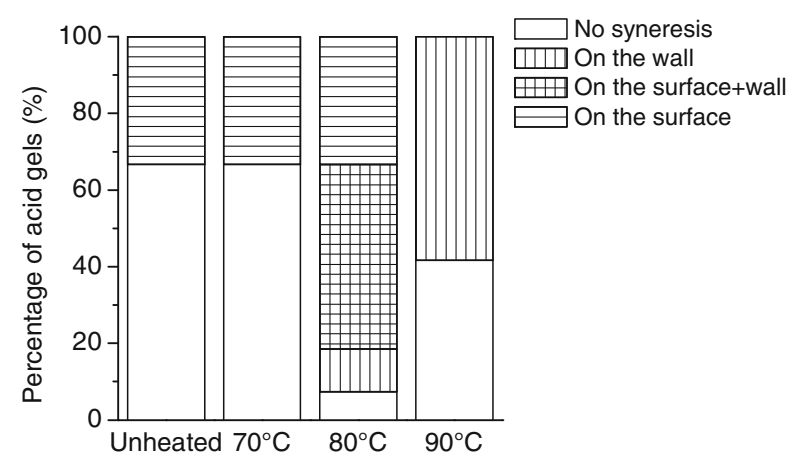

Fig. 7 Proportion of set acid milk gels at $\mathrm{pH} 4.6$ from unheated milk or milk heat-treated at 70,80 or $90{ }^{\circ} \mathrm{C}$ subjected to no syneresis, syneresis on the surface, wall syneresis or surface and wall syneresis as determined by the backscattering profiles obtained by Turbiscan MA2000. The proportions were calculated from 12 samples for acid milk gels from unheated milk or milk heat-treated at 70 or $90{ }^{\circ} \mathrm{C}$ and 27 samples for acid milk gels from milk heat-treated at $80^{\circ} \mathrm{C}$

acid milk gels were taken at the end of acidification at $\mathrm{pH} 4.6$ (Fig. 8b). A homogeneous gel was obtained for one sample (top of the figure) whereas extensive syneresis along the wall of the tube was evident for the second one (bottom of the figure) especially at the laser height of $24 \mathrm{~mm}$ (grey line). In agreement with observations by SMLS (Fig. 6b) and DWS (Fig. 8a), the rough surface appearance of the gels confirmed the presence of macroscopic zones of localized trapped serum, contributing to the non-homogeneity of the gel along its height.

In summary, under the various conditions of heat treatment, two consequences of gel restructuring were identified: syneresis on the gel surface and wall syneresis. Moreover, it has been shown that light scattering techniques proved to be very efficient tools to detect these different consequences of the gel rearrangement which lead to syneresis during gel formation, before visual defects are observable. Besides, such phenomena were not systematically noticeable by classical rheological measurements.

\subsection{Proposed model for syneresis in acid milk gels}

A schematic representation of the two consequences of gel restructuring occurring in acid milk gels, namely 'surface syneresis' and 'wall syneresis' is proposed in Fig. 9. In

Fig. 8 a Elasticity index as a function of $\mathrm{pH}$ during acidification by $1.25 \mathrm{wt} \%$ GDL at $43^{\circ} \mathrm{C}$ for two repeated milk heat-treated at $90^{\circ} \mathrm{C}$; b Visual appearance of set acid gels from milk heat-treated at $90{ }^{\circ} \mathrm{C}$ corresponding to the two repeated gels analyzed in Fig. 5 at $\mathrm{pH} 4.6$ (the pictures at the top and bottom correspond to the gel represented by solid and dotted lines, respectively). The grey lines on the pictures correspond to the laser height of DWS measurement

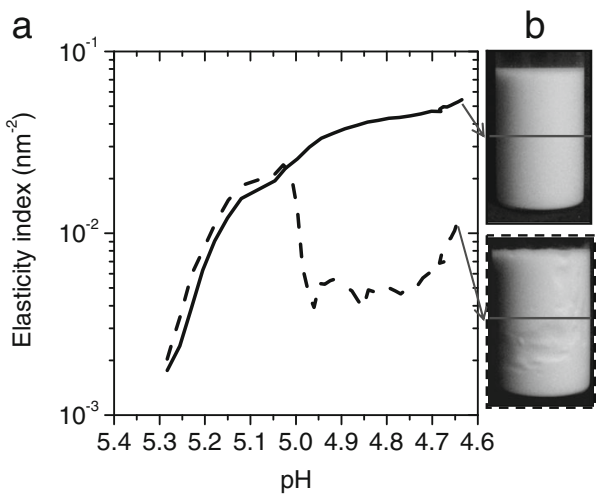



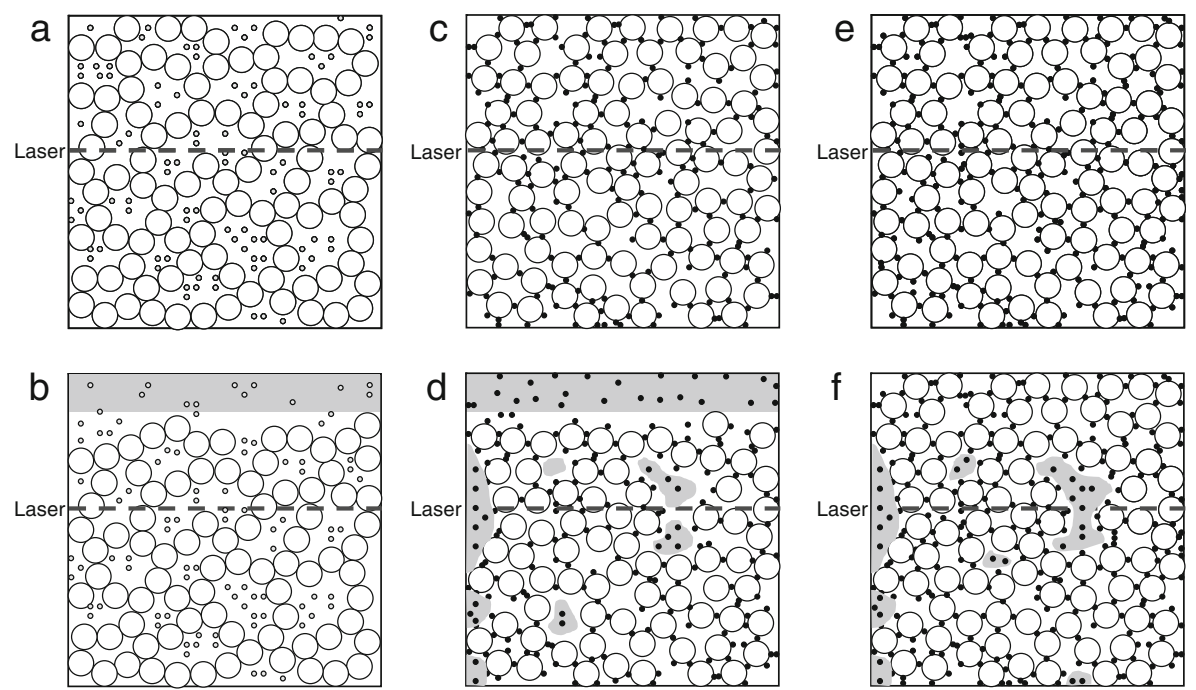

Casein micelle particle
- Denatured whey protein
- Native whey protein

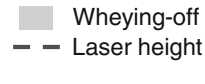

Fig. 9 Schematic representation of acid milk gel microstructures from $\mathbf{a}$ and $\mathbf{b}$ unheated milk or low heated milk, $\mathbf{c}$ and $\mathbf{d}$ medium heat-treated and $\mathbf{e}$ and $\mathbf{f}$ high-heat-treated milk, as detected by light-scattering techniques (adapted from Famelart et al. 2004). a, c and e represent the gels in case of absence of syneresis; $\mathbf{b}, \mathbf{d}$ and $\mathbf{f}$ represent the gels after syneresis occurred in a time of storage of $24 \mathrm{~h}$

the two situations, serum is expelled from the network due to gel rearrangement, which results in phase separation and a non-homogeneous system. However, a distinction between the consequences of gel restructuring leading to syneresis can be made.

Figure $9 \mathrm{~b}$ and $\mathrm{d}$ illustrates the apparition of syneresis on the surface that was detected by SMLS technique (Figs. 6a, c and 7). Extensive whey separation on the surface has previously been observed during and after acidification of milk (Lucey et al. 1997a, 1998b). Syneresis on gel surface is particularly visible for gels made from unheated or low-heat-treated milk (Lucey et al. 2001). This can be explained by a specific microstructure since the large pores, and thus the high permeability of the gels from unheated milk, make it easier for whey to move to the gel surface while rearranging (Fig. 9a) (Aichinger et al. 2003; Lucey et al. 2001; van Vliet et al. 2004b). Moreover, the interparticle rearrangements during aggregation due to weak protein-protein interaction may involve the formation of water-channels within the network (Renard et al. 2006; van Vliet et al. 2004a), acting as liquid transporters to the surface (Fig. 9b).

The second consequence of gel restructuring leading to syneresis called 'wall syneresis' is shown in Fig. 9f. It may not be detected by rheology because of its macroscopic nature and pieces of gel sticking to the cell wall, but it strongly affected SMLS (Figs. 6b, $d$ and 7) and may affect DWS signals (Fig. 8). It seems that gels made from severely-heated milk $\left(>80{ }^{\circ} \mathrm{C}\right)$ showed a greater susceptibility to wall syneresis (Fig. 8). It has been well-established in the literature that a high treatment of milk resulted in a 'branched' microstructure with small pores due to the active participation of denatured whey proteins to the gel network (Fig. 9e) (Donato and Guyomarc'h 2009; 
Famelart et al. 2004; Lucey et al. 1998b, 2001). As a consequence, the low water retention should prevent extensive whey separation as commonly believed. Nevertheless, it is important to state that whey separation can also be a consequence of the contraction of the gel network (Aichinger et al. 2003). In gels made from highheat-treated milk, the continued aggregation of casein particles and incorporation of denatured whey proteins may cause local stresses in the networks (Lucey et al. 1998b). This mechanism can lead to localized cracks and the formation of whey-enriched zones (Fig. 9f), and thus to the apparition of rough surfaces, as seen in Fig. 8b. However, it should be noted that DWS signal may be affected by wall syneresis only if the zone of whey pockets void of macroscopic gel and thus containing small particles free to move in the serum phase corresponded to the laser height of measurement.

It should be mentioned that both 'surface syneresis' and 'wall syneresis' occurring at the same time can be found in intermediate-heat-treated gels, as in the case of the application of a heat treatment of $80^{\circ} \mathrm{C}$ for $7 \mathrm{~min}$ (Fig. 9d). Moreover, the susceptibility to wall syneresis is not only governed by the density of the network and the resistance of the protein chains to deformation, but also by the container's properties. Since the whey remained in confined zones during and after the acidification process, the casein network was strongly sticking to the walls of the glass tube. Therefore, further research should be carried out on surface properties of glass, material packaging (glass, polystyrene, stoneware) or surface topology to modify the adhesion of protein networks to the wall and thus syneresis.

\section{Conclusion}

Acid milk gelation and syneresis detection were studied using two light scattering techniques, SMLS and DWS, in comparison to classically-used rheology. Strong correlations were highlighted between the DWS behaviour and the rheological measurements for the gel point detection but also during the kinetics of gel formation. Under various conditions of milk heat treatment, which lead to different gel properties, DWS proved to bring additional information to rheology. The combination of techniques made it possible to distinguish two consequences of gel restructuring leading to syneresis, described respectively as 'surface syneresis' and 'wall syneresis'. The proposed model for syneresis in acid milk gels associates the type of syneresis with specific gel microstructures obtained by various milk heat treatments. The use of DWS could therefore be of great interest in syneresis prevention in industrial environments such as yoghurt manufacturing, particularly with the development of user-friendly instruments.

\section{References}

Aichinger PA, Michel M, Servais C et al (2003) Fermentation of a skim milk concentrate with Streptococcus thermophilus and chymosin: structure, viscoelasticity and syneresis of gels. Colloid Surface B 31:243-255

Alexander M, Dalgleish DG (2005) Interactions between denatured milk serum proteins and casein micelles studied by diffusing wave spectroscopy. Langmuir 11380-11386 
Alexander M, Dalgleish DG (2007) Diffusing wave spectroscopy of aggregating and gelling systems. Curr Opin In 12:179-186

Alexander M, Piska I, Dalgleish DG (2008) Investigation of particle dynamics in gels involving casein micelles: a diffusing wave spectroscopy and rheology approach. Food Hydrocoll 22:1124-1134

Brunel L (2010) Procédé de caractérisation rhéologique d'un milieu complexe. WO 2010130766:A1

Corredig M, Alexander M (2008) Food emulsions studied by DWS. Trends Food Sci Tech 19:67-75

Dalgleish DG, Alexander M, Corredig M (2004) Studies of the acid gelation of milk using ultrasonic spectroscopy and diffusing wave spectroscopy. Food Hydrocoll 18:747-755

Donato L, Guyomarc'h F (2009) Formation and properties of the whey protein/K-casein complexes in heated skim milk—a review. Dairy Sci Technol 89:3-29

Ercili-Cura D, Lille M, Legland D, Gaucel S, Poutanen K, Partanen R, Lantto R (2013) Structural mechanisms leading to improved water retention in acid milk gels by use of transglutaminase. Food Hydrocoll 30:419-427

Famelart MH, Tomazewski J, Piot M, Pezennec S (2004) Comprehensive study of acid gelation of heated milk with model protein systems. Int Dairy J 14:313-321

Gastaldi E, Lagaude A, Tarodo de la Fuente BT (1996) Micellar transition state in casein between pH 5.5 and 5.0. J Food Sci 61:1-7

Guyomarc'h F, Law AJ, Dalgleish DG (2003) Formation of soluble and micelle-bound protein aggregates in heated milk. J Agr Food Chem 51:4652-4660

Haque A, Richardson RK, Morris ER (2001) Effect of fermentation temperature on the rheology of set and stirred yoghurt. Food Hydrocoll 15:593-602

Heertje I, Visser J, Smits P (1985) Structure formation in acid milk gels. Food Microst 4:267-277

Hemar Y, Singh H, Horne DS (2004) Determination of early stages of rennet-induced aggregation of casein micelles by diffusing wave spectroscopy and rheological measurements. Curr Appl Phys 4:362-365

Holt C (1992) Structure and stability of the bovine casein micelle. In: Afinsen CB, Sall JDED, Richards FK, Eisenberg DS (eds) Advances in protein chemistry, pp 63-151

Horne DS (1999) Formation and structure of acidified milk gels. Int Dairy J 9:261-268

Horne DS, Hemar Y, Davidson CM (2003) Diffusing wave spectroscopy studies of gel formation. In: Dickinson E, van Vliet T (eds) Food colloids - biopolymers and materials. RSC, Cambridge, pp 17-25

Kalab M, Emmons DB (1975) Milk-gel structure. IV. Microstructure of yoghurts in relation to the presence of thickening agents. J Dairy Res 42:453-458

Livney YD, Corredig M, Dalgleish DG (2003) Influence of thermal processing on the properties of dairy colloids. Curr Opin Colloid In 8:359-364

Lucey JA, van Vliet T, Grolle K et al (1997a) Properties of acid casein gels made by acidification with glucono-delta-lactone. 2. Syneresis, permeability and microstructural properties. Int Dairy J 7:389-397

Lucey JA, van Vliet T, Grolle K et al (1997b) Properties of acid casein gels made by acidification with glucono-delta-lactone. 1. Rheological properties. Int Dairy J 7:381-388

Lucey JA, Tamehana M, Singh H, Munro PA (1998a) A comparison of the formation, rheological properties and microstructure of acid skim milk gels made with a bacterial culture or glucono-delta-lactone. Food Res Int 31:147-155

Lucey JA, Teo CT, Munro PA, Singh H (1998b) Microstructure, permeability and appearance of acid gels made from heated skim milk. Food Hydrocoll 12:159-165

Lucey JA, Munro PA, Singh H (1999) Effects of heat treatment and whey protein addition on the rheological properties and structure of acid skim milk gels. Int Dairy J 9:275-279

Lucey JA, Tamehana M, Singh H, Munro PA (2001) Effect of heat treatment on the physical properties of milk gels made with both rennet and acid. Int Dairy J 11:559-565

Mengual O, Meunier G, Cayré I et al (1999) TURBISCAN MA 2000: multiple light scattering measurement for concentrated emulsion and suspension instability analysis. Talanta 50:445-456

Nicolai T (2007) Food characterisation using scattering methods. In: McClements DJ (ed) Understanding and controlling the microstructure of complex foods, pp 288-310

Renard D, van de Velde F, Visschers RW (2006) The gap between food gel structure, texture and perception. Food Hydrocoll 423-431

Sandra S, Alexander M, Dalgleish DG (2007) The rennet coagulation mechanism of skim milk as observed by transmission diffusing wave spectroscopy. J Colloid Interf Sci 308:364-373

Stradner A, Romer S, Urban C, Schurtenberger P (2001) Aggregation and gel formation in biopolymer solutions. Progr Coll Pol Sci 118:136-140

van Vliet T, Lakemond C, Visschers RW (2004a) Rheology and structure of milk protein gels. Curr Opin Colloid In 9:298-304 
van Vliet T, Lucey JA, Grolle K, Wastra P (2004b) Rearrangements in acid-induced casein gels during and after gel formation. In: Dickinson E, Bergenstahl B (eds) Food colloids-proteins, lipids and polysaccharides. RSC, Cambridge, pp 335-345

Weitz DA, Pine DJ (1993) Diffusing-wave spectroscopy. In: In: W. Brown (Ed.), Dynamic light scattering: the method and some applications. Oxford University Press. pp 652-670

Xu Z-M, Emmanouelidou DG, Raphaelides SN, Antoniou KD (2008) Effects of heating temperature and fat content on the structure development of set yogurt. J Food Eng 85:590-597. doi:10.1016/j. jfoodeng.2007.08.021 